\title{
A EDUCAÇÃO AMBIENTAL COMO CAMINHO PARA O DESENVOLVIMENTO SUSTENTÁVEL
}

\author{
Nei Antonio Nunes ${ }^{1}$ \\ Alberto Essondon Banhal ${ }^{2}$
}

RESUMO: O trabalho objetiva revisar e refletir sobre a Educação Ambiental (EA) como caminho para desenvolvimento Sustentável, no campo da educação. Este último, mais especificamente, no ensino. Para tanto, parte da historiedade e da logicidade do assunto, em sua transitoriedade, constituindo-se em um artigo de revisão. Em decorrência, este estudo foi realizado por meio de uma abordagem exploratória, com método qualitativo, de raciocínio indutivo, tomando como base revisão bibliográfica e documental para a apropriação conceitual. Sua relevância se volta para a abordagem de dois assuntos inter, multi e transdisciplinares, que se revelam e se complementam em um entendimento social mais amplo. As reflexões aqui tratadas sob o contexto da Educação ambiental apontam para o desafio do respectivo campo. Este deve conceber e disseminar conhecimentos científicos oriundos e inerentes à Educação e desenvolvimento sustentável, que sejam capazes de operar com a transformação do paradigma social atual, no qual esta ciência se amalgama, para aquele que se espera no futuro: a educação ambiental contextualizada e articulada com o paradigma do desenvolvimento sustentável. Conclui que o desafio de se incorporar a educação para o desenvolvimento sustentável no ensino deve ser enfrentado por meio da Educação Ambiental. Educação Ambiental se constitui numa forma abrangente de educação, que se propõe atingir todos os cidadãos, através de um processo participativo permanente que procura incutir uma consciência crítica sobre a problemática ambiental.

Palavras-chave: Educação ambiental. Desenvolvimento. Sustentabilidade.

ABSTRACT: The work aims to review and reflect on Environmental Education (EE) as a path to sustainable development in the field of education. The latter, more specifically, in teaching. To do so, it starts from the history and logic of the subject, in its transience, constituting a review article. As a result, this study was carried out through an exploratory approach, with a qualitative method, of inductive reasoning, based on a bibliographic and documentary review for conceptual appropriation. Its relevance turns to the approach of two inter, multi and transdisciplinary issues, which reveal and complement each other in a broader social understanding. The reflections treated here under the context of Environmental Education point to the challenge of the respective field. This must conceive and disseminate scientific knowledge arising from and inherent to Education and sustainable development, which are capable of operating with the transformation of the current social paradigm, in which this science is amalgamated, to what is expected in the future: contextualized and articulated environmental education. with the paradigm of sustainable development. It concludes that the challenge of incorporating education for sustainable development into teaching must be faced through Environmental Education. Environmental Education is a comprehensive form of education, which aims to reach all citizens, through a permanent participatory process that seeks to instill a critical awareness of environmental issues.

Keywords: Environmental education. Development. Sustainability.

\footnotetext{
${ }^{I}$ Doutorando em Sociologia Política da Universidade Federal de Santa Catarina (UFSC). Professor de PPGA na UNISUL.E-mail: neinunes@bol.com.br

2 Mestrando em Universidade do Sul de Santa Catarina (UNISUL) Email: albertoessondonbanhal@gmail.com.br.
} 


\section{INTRODUÇÃO}

O relacionamento que o ser homem vem tendo com a natureza foi sempre de exploração. O cenário ambiental sofre degradações por consequência do desenvolvimento urbano e a pouca sensibilização da sociedade quanto à preservação do meio em que vivem (POTT; ESTRELA, 2017; BEZERRA et al., 2019) ${ }^{3}$. A educação ambientalé uma ferramenta indispensável na transformação comportamental das pessoas com relação à utilização sustentável das riquezas naturais. Além disso, possibilita reconhecer o ambiente como intrínseco à sua vida, percebendo sua importância e identificando-se como parte dos seus componentes (ASSIS; CHAVES, 2013) ${ }^{4}$.

Desde a antiguidade que existem estudos e denúncias acerca de problemas ambientais em virtude da ação antrópica, resultando na edição de leis, decretos, normas de caráter proibitivo ou disciplinador da interferência humana sobre os ecossistemas. Podemos citar grandes doutrinadores, filósofos, dentre outras personalidades que em seus trabalhos, tanto na esfera nacional e internacional, sempre contribuíram com estudos e divulgação de situações de degradação ambiental podendo ser citados: Platão, na Antiguidade; Friedrich Engels, em 1825; Charles Darwin, em I859; Joaquim Nabuco, em ı883; Theodore Roosevelt, em I9I4; Aldo Leopold e René Dubos, em 1945; Rachel Carson, em 1962..$^{5}$ Estas denúncias configuram o que Edgar Morin denomina de uma situação de Agonia Planetária, asseverando que "Durante o século XX, a economia, a demografia, o desenvolvimento, a ecologia se tornaram problemas que doravante dizem respeito a todas as nações e civilizações, ou seja, ao planeta como um todo" ${ }^{6}$. E como um dos antídotos para este "status quo" apresentamos algumas ideias do mesmo educador francês Edgard Morin e sua concepção de "cabeças bem-feitas”, de forma a capacitar o educando a elaborar sua própria conclusão a partir de uma compreensão do contexto e do que é complexo, de um pensamento ecologizante.

\footnotetext{
${ }^{3}$ POTT, C. M.; ESTRELA, C. C. Histórico ambiental: desastres ambientais e o despertar de um novo pensamento. Estudos Avançados, v. 3I, n. 89, p.271-283, 2017.

${ }^{4}$ ASSIS, A. R. S.; CHAVES, M. R. A degradação ambiental e a sustentabilidade. Revista Nacional de Gerenciamento de Cidades, v. or, n. 02, p.58-74, 2013

5 PHILIPPI JR, Arlindo, CAFFÉ ALVES, Alaôr. Curso interdisciplinar de direito ambiental. São Paulo: Manole, 2005. p. I4I.

${ }^{6}$ MORIN, Edgar. Terra-pátria. 2. ed. Porto Alegre: Sulina, 1995. p. 69.
} 
Neste contexto, a escola torna-se o ponto de partida para o início das discussões sobre as questões relacionadas ao meio ambiente, sendo estas trabalhadas de forma interdisciplinar para a formação de cidadãos críticos e sensibilizados para com os problemas ambientais.

Segundo Abílio e Guerra (2005) ${ }^{7}$, a escola, tendo em vista a importância que exerce no processo de formação social, cultural, humana e ética da sociedade, se apresenta como um dos locais mais propícios para o desenvolvimento de atividades com enfoque educativo relacionado ao ambiente em que vivemos.

A educação ambiental figura como instrumento na promoção do desenvolvimento sustentável, vez que, amparada na ética ecológica, gera uma conscientização acerca da preservação do planeta. Ou seja, devido ao seu compromisso com o desenvolvimento humano e ambiental, auxilia para o despertar da percepção sustentável por meio de mudanças nos valores, nas ações, nos pensamentos, nas metodologias, entre outros hábitos humanos, sob o fundamento de uma ética ambientalista, assim entendida como a exteriorização dessa consciência (MASSINE, 2010) $)^{8}$.

Desta maneira, este trabalho de revisão de literatura tem como objetivo principal o de demonstrar sobre a educação como caminho para desenvolvimento sustentável no campo da educação, previstos nos documentos normativos internacionais e na legislação interna, para fundamentar o desenvolvimento sustentável.

\section{METODOLOGIA}

O método que utilizamos foi o ARL - Artigo de Revisão de Literatura -, apoiado por Hohendorff $(2011)^{9}$, quando afirma que os ARLs são construídos pela revisão de literatura já existente - textos de artigos e livros que discutem o tema proposto - com métodos e organização a partir de passos para a construção de uma

\footnotetext{
${ }^{7}$ ABÍLIO, F.J. P.; FLORENTINO, H. da S. Percepção e atividades integradoras de educação ambiental com educandos do ensino médio de Soledade-PB. João Pessoa: UFPB, 2008.

${ }^{8}$ MASSINE, M.C.L. Sustentabilidade e Educação Ambiental - Considerações acerca da política nacional de educação ambiental - A Conscientização ecológica em foco. Anais do XIX Encontro Nacional do CONPEDI, Fortaleza - CE, zoro.

${ }^{9}$ HOHENDORFF, J. V. Como escrever um artigo de revisão de literatura. In: KOLLER, S. H.; COUTO, M. C.; HOHENDORFF, J. V. Manual de produção científica. ı ed., vol. r. Porto Alegre, RS, Brasil: Porto, 2014. p. 19r.
} 
nova informação. Buscou-se também a construção de reflexões mediante informações e conhecimentos gerados por pesquisadores na temática pertinente e relevante.

O exercício dessa dinâmica permite que os traços das culturas que se chocam na educação ambiental superem as divisões estruturais e abram espaço para o diálogo entre os diferentes, permite que a releitura do senso comum através das linguagens cientificas normatizadas conduzam a comunidade escolar rumo a um desenvolvimento sustentável na forma de se produzir conhecimento, despertando o interesse para aquilo que há de mais importante na educação ambiental: o contato com a socialização de atores de origens tão distintas, através da tolerância, do exercício do diálogo, do cuidado com a natureza e do reconhecer a importância da existência do outro.

\section{CONTEXTUALIZAÇÃO DA EDUCAÇÃO AMBIENTAL (EA)}

Muitos conceitos, objetivos, diretrizes, metodologias e outras questões sobre a EA, associada ao desenvolvimento sustentável, foram desenvolvidos em diversas conferências internacionais e nacionais sobre meio ambiente, muitas delas tendo a Unesco como promotora ou apoiadora.

Segundo Barbieri e Silva (201I $)^{\mathrm{IO}}$, as origens dessa EA estão ligadas à própria criação da Unesco, em 1946, órgão da ONU que iniciou o debate em torno da educação de um modo geral e da EA em particular, em termos globais e por meio da mobilização de governos e entidades da sociedade civil. A criação desse órgão faz parte das iniciativas do imediato pós-guerra para construir condições sociais e econômicas que garantissem a paz de forma duradoura.

Em uma de suas iniciativas, a Conferência sobre a Biosfera, realizada em Paris, em 1968, foi criado o programa Homem e Biosfera (MaB, do inglês Man and the Biosphere), com vistas a ampliar os entendimentos da relação entre os humanos e o meio ambiente, e promover o conhecimento, a prática e os valores humanos para implantar as boas relações entre as populações e o meio ambiente em todo o planeta.

\footnotetext{
${ }^{\text {Io } B A R B I E R I, ~ J o s e ́ ~ C a r l o s ; ~ S I L V A, ~ D i r c e u ~ d a . ~ D e s e n v o l v i m e n t o ~ s u s t e n t a ́ v e l ~ e ~ e d u c a c ̧ a ̃ o ~ a m b i e n t a l: ~}$ uma trajetória comum com muitos desafios.RAM, Rev. Adm. Mackenzie (Online), São Paulo, v. I2,n. 3,p. 5I-82,JunezorI . Disponível em: 〈http://www.scielo.br/scielo.php?script=sci_arttext\&pid=Si678$69712011000300004 \& \operatorname{lng}=$ en\& $\mathrm{nrm}=\mathrm{iso}>$. Acesso em: 16 jan. 2022.
} 
Essa conferência pode ser considerada o marco inicial do movimento pelo desenvolvimento sustentável. Mesmo depois que outros órgãos da ONU assumiram os debates, como a Assembleia Geral da ONU (1966) ${ }^{\mathrm{II}}$ e o Programa das Nações Unidas para o Meio Ambiente (Pnuma), a Unesco continuou dando sua contribuição para esse movimento nos campos da educação e cultura, suas áreas de atuação específica, como será mostrado mais adiante.

Durante a Conferência das Nações Unidas para o Meio Ambiente Humano (CNUMAH), realizada em Estocolmo, em $1972^{12}$, foram criados alguns instrumentos para tratar de problemas sociais e ambientais planetários, como a Declaração sobre o Ambiente Humano, com 26 princípios voltados para orientar a construção de ambiente que harmonize os aspectos humanos e naturais, considerados essenciais para o beestar dos humanos e para que possam gozar de todos os direitos fundamentais Barbieri \& Silva, 20II $)^{13}$.

De acordo com um desses princípios, é indispensável um trabalho de educação em questões ambientais, dirigido para jovens e adultos. A Conferência de Estocolmo firmou as bases para um novo entendimento acerca das relações entre o ambiente e o desenvolvimento socioeconômico.

O primeiro princípio dessa Declaração é um exemplo dessa visão que integra questões sociais e ambientais, o que confere sentido para a expressão sócioambiental:

\begin{abstract}
homem tem o direito fundamental à liberdade, à igualdade e ao desfrute de condições de vida adequadas em um meio ambiente de qualidade tal que lhe permita levar uma vida digna e gozar de bem-estar, tendo a solene obrigação de proteger e melhorar o meio ambiente para as gerações presentes e futuras (CNUMAH, 1972, Princípio I, p. I I ${ }^{\mathrm{I4}}$.
\end{abstract}

Após a Conferência de Estocolmo de 1972, a EA passou a receber atenção especial em praticamente todos os fóruns relacionados com a temática do

\footnotetext{
"' ASSEMBLÉIA GERAL DAS NAÇÕES UNIDAS. Pacto internacional dos direitos econômicos, sócias e culturais. Resolução 2.200-A, 1966. Ratificado pelo Brasil em 24 jan. 1992.

${ }^{12}$ CNUMAH. Declaração de Estocolmo sobre o ambiente humano. Estocolomo, 1972. Disponível em:http://www.educacaoambiental.pro.br/victor/unidade/DeclaraAmbienteHumano.pdf Acesso em: 20 janeiro 2022.

${ }^{13}$ Barbieri, J. C. \& Silva, D. (2011). Desenvolvimento sustentável e educação ambiental: uma trajetória comum com muitos desafios. Revista de Administração Mackenzie, São Paulo, SP, 12(3), 51-82, maio/jun.

${ }^{14}$ CNUMAH. Declaração de Estocolmo sobre o ambiente humano. Estocolomo, 1972. Disponível em:http://www.educacaoambiental.pro.br/victor/unidade/DeclaraAmbienteHumano.pdf Acesso em: 20 janeiro 2022 .
} 
desenvolvimento e do meio ambiente. Dela resultou a criação do Programa das Nações Unidas para o Meio Ambiente (Pnuma), que viria a dividir com a Unesco as questões relativas à EA no âmbito das Nações Unidas(Barbieri \& Silva, 20II) ${ }^{15}$.

Foi estabelecido um plano de trabalho com iıo resoluções, e uma delas se refere à necessidade de implantar a EA de caráter interdisciplinar com o objetivo de preparar o ser humano para viver em harmonia com o meio ambiente (Resolução no 96). Para cumprir essa resolução, a Unesco e o Pnuma criaram o Programa Internacional de Educação Ambiental (Piea), com o objetivo de promover o intercâmbio de ideias, informações e experiências em EA entre as nações de todo o mundo, fomentar o desenvolvimento de atividades de pesquisa que melhorem a compreensão e a implantação da EA, promover o desenvolvimento e a avaliação de materiais didáticos, currículos, programas e instrumentos de ensino, favorecer o treinamento de pessoal para o desenvolvimento da EA e dar assistência aos Estados membros com relação à implantação de políticas e programas de EA.

Uma das primeiras atividades do Piea foi a realização de um Seminário Internacional sobre Educação Ambiental em 1975, no qual foi aprovada a Carta de Belgrado, um importante documento sobre diversas questões pertinentes à EA, sob a perspectiva do desenvolvimento sustentável, embora, nessa época, ainda não se usasse essa expressão, a não ser em círculos muito restritos (Barbieri \& Silva, 20II) ${ }^{16}$.

A Carta de Belgrado estabeleceu que a meta básica da ação ambiental seria melhorar todas as relações ecológicas, incluindo as relações do ser humano entre si e com os demais elementos da natureza, bem como desenvolver uma população mundial consciente e preocupada com o meio ambiente e com os problemas associados a ele, com conhecimento, habilidade, motivação, atitude e compromisso para atuar de forma individual e coletiva na busca por soluções para os problemas atuais e para a prevenção de novos problemas ${ }^{17}$.

\footnotetext{
is BARBIERI, José Carlos; SILVA, Dirceu da. Desenvolvimento sustentável e educação ambiental: uma trajetória comum com muitos desafios. RAM, Rev. Adm. Mackenzie (Online), São Paulo, v. i2,n. 3,p. 51-82,June2oII . Disponível em: $\langle$ http://www.scielo.br/scielo.php?script=sci_arttext\&pid=SI678$69712011000300004 \& \operatorname{lng}=$ en $\& n r m=$ iso $>$. Acesso em: 16 jan. 2022.

${ }^{16}$ Ibidem;

${ }^{17}$ Carta de Belgrado. (1975). Uma estrutura global para a educação ambiental. Recuperado em i6 jan. 2022, de http://www.fzb.rs.gov.br/upload/2013050815564icarta_de_belgrado.pdf.
} 
O público em geral, o principal alvo da EA, é constituído por todos os integrantes da educação formal e não formal. Os primeiros compreendem os alunos e professores de todos os níveis, da pré-escola ao ensino superior e o treinamento profissional; os segundos incluem jovens e adultos, individualmente considerados ou em grupos, de todos os segmentos da sociedade: trabalhadores, administradores, profissionais liberais, entre outros. Os objetivos da educação ambiental, de acordo com a Carta de Belgrado (1975), são:

I. Conscientização: contribuir para que indivíduos e grupos adquiram consciência e sensibilidade em relação ao meio ambiente como um todo e quanto aos problemas relacionados com ele.

2. Conhecimento: propiciar uma compreensão básica sobre o meio ambiente, principalmente quanto às influências do ser humano e de suas atividades.

3. Atitudes: propiciar a aquisição de valores e motivação para induzir uma participação ativa na proteção ao meio ambiente e na resolução dos problemas ambientais.

4. Habilidades: proporcionar condições para que os indivíduos e grupos sociais adquiram as habilidades necessárias a essa participação ativa.

5. Capacidade de avaliação: estimular a avaliação das providências efetivamente tomadas em relação ao meio ambiente e aos programas de educação ambiental.

6. Participação: contribuir para que os indivíduos e grupos desenvolvam o senso de responsabilidade e de urgência com relação às questões ambientais.

O público em geral, o principal alvo da EA, é constituído por todos os integrantes da educação formal e não formal. Os primeiros compreendem os alunos e professores de todos os níveis, da pré-escola ao ensino superior e o treinamento profissional; os segundos incluem jovens e adultos, individualmente considerados ou em grupos, de todos os segmentos da sociedade: trabalhadores, administradores, profissionais liberais, entre outros.

\section{I. CONCEITOS DE EDUCAÇÃO AMBIENTAL SEGUNDO ALGUNS AUTORES.}

Não é possível definir educação em um único conceito, porém no seu sentido mais amplo, podemos dizer que significa o meio em que os hábitos, costumes 
e valores de uma comunidade são transferidos de pais para filhos, aonde ela vai se formando através de ocorrências presenciadas e experiências vividas por cada indivíduo ao longo da sua vida.

Também podemos dizer que a educação é um processo de atuação de uma comunidade sobre o desenvolvimento do indivíduo a fim de que ele possa atuar em uma sociedade pronta para a busca da aceitação dos objetivos coletivos. Para tal educação, devemos considerar o homem no plano físico e intelectual consciente das possibilidades e limitações, capaz de compreender e refletir sobre a realidade do mundo que o cerca, devendo considerar seu papel de transformação social como uma sociedade que supere nos dias atuais a economia e a política, buscando solidariedade entre as pessoas, respeitando as diferenças individuais de cada um. (OLIVEIRA, $2009)^{18}$.

Segundo o dicionário Aurélio, educação é o "processo de desenvolvimento da capacidade física, intelectual e moral da criança e do ser humano em geral, visando à sua melhor integração individual e social”.

A preservação do meio ambiente depende muito da ação das gerações presentes e futuras, e o que estão dispostas a fazer para diminuir o impacto ambiental das suas ações, por esse motivo, a educação ambiental é de extrema importância e deve ser abordada nas escolas, para que todos desenvolvam uma consciência ambiental e tenham atitudes responsáveis em relação ao meio ambiente.

De acordo com a UNESCO, Educação Ambiental é um processo permanente no qual os indivíduos e a comunidade tomam consciência do meio ambiente em que vivem e adquirem conhecimentos, habilidades, experiências, valores e a determinação que os tornam capazes de agir, individual ou coletivamente, na busca de soluções para os problemas ambientais, presentes e futuros. (UNESCO, $1987)^{19}$.

\footnotetext{
I8 OLIVEIRA, Daniel Barbosa de. Material de Apoio sobre Educação: Conceito de Educação. Paracatu/SC. 2009. Disponível em: 〈http://www.ebah.com.br/content/ABAAAATl8AJ/conceitoeducacao $>$. Acesso em is set 2009.

${ }^{19}$ UNESCO, 1987. Congreso Internacional UNESCO/PNUMA sobre la educacion y la Formacion Ambientales, Moscou. In: Educação Ambiental, Situação Espanhola e Estratégia Internacional. DGMA-MOPU, Madrid.
} 
Segundo Abílio e Guerra $(2005)^{20}$, a escola, tendo em vista a importância que exerce no processo de formação social, cultural, humana e ética da sociedade, se apresenta como um dos locais mais propícios para o desenvolvimento de atividades com enfoque educativo relacionado ao ambiente em que vivemos.

Conforme Tristão (2010) ${ }^{21}$, a educação ambiental passa a ser compreendida não só como um modismo passageiro, mas como um caminho, que grupos de profissionais ambientalistas e de outras áreas de atuação e de conhecimento se veem motivados a seguir. Com isso, buscando a conscientização e o apoio de jovens profissionais e estudantes que estão preocupados com a preservação do meio ambiente e sobrevivência do planeta, pode-se perceber que este processo irá se desenvolver, mas de forma lenta e gradual.

Nesse contexto, Almeida $(2006)^{22}$ aponta que as questões ambientais são capazes de sensibilizar aqueles em que a visão adquirida sobre a natureza está associada a crenças filosóficas, religiosas e morais. No entanto, as experiências indicam o quanto ainda precisa ser feito, bem como a grande importância da participação da universidade para o desenvolvimento e formação de seres humanos mais preocupados com a sobrevivência do meio ambiente.

Para Carvalho $(2006)^{23}$, a educação ambiental é considerada inicialmente como uma preocupação dos movimentos ecológicos com a prática de conscientização, que seja capaz de chamar a atenção para o uso excessivo dos recursos naturais, assim como ao seu esgotamento, fazendo com que haja o envolvimento direto dos cidadãos em ações sociais ambientalmente corretas.

A educação ambiental é um tema em crescimento nos dias de hoje já que se percebe a necessidade de uma melhoria do mundo em que vivemos, pois é facilmente notado que estamos retrocedendo, deixando cada vez mais de lado nossa qualidade de

\footnotetext{
${ }^{20}$ ABÍliO, F.J. P.; GUERRA, R. A. T. (Org.). A questão ambiental no ensino de Ciências e a formação continuada de professores de ensino fundamental. João Pessoa: UFPB/FUNAPE, 2005.

${ }^{2 \mathrm{I}}$ Tristão, M. \& Jacobi, P. R. (2010). Educação ambiental e os movimentos de um campo de pesquisa. São Paulo: Annablume.

${ }^{22}$ Almeida, J. R. (2006). Gestão ambiental: para o desenvolvimento sustentável. Rio de Janeiro: Thex.

${ }^{23}$ Carvalho, I. C. M. (20II). Educação Ambiental: a formação do sujeito ecológico (5a ed.). São Paulo, SP: Cortez.
} 
vida de um modo geral, seja pelo curto espaço de tempo ou pelos compromissos em excesso, fazendo com que nossas obrigações diárias fiquem de lado (Guedes, 2006) ${ }^{24}$.

Cuba (2010) salienta que a educação ambiental se caracteriza por adotar a gestão ambiental como princípio educativo do currículo e por centrar-se na ideia da participação dos indivíduos na gestão dos seus respectivos lugares: seja a escola, a rua, o bairro, o lugar das relações que mantém o cotidiano. Sendo assim entende-se que o principal papel da educação ambiental é contribuir para que as pessoas adotem uma nova postura com relação ao seu próprio lugar.

Segundo Travassos (2004) ${ }^{25}$ o conceito de Educação Ambiental parece não ter sido bem assimilado ainda pelas escolas. Lobato (1999), apud Travassos (2004) afirma que a EA está sendo considerada uma modalidade educacional separada da educação, ela está sendo dominada por uma visão técnica de gestão e reduzida ao conservacionismo ou a reciclagem de materiais. Segundo o autor, ainda predomina um pensamento unidirecional e ressalta a importância da participação de todas as disciplinas na abordagem dos projetos relacionados à prática ambiental.

Nessa perspectiva, segundo Moreira $(2002)^{26}$, o sistema educacional deve buscar ações e estratégias para que os envolvidos no processo de EA entendam as relações atuais de produção e de consumo. O professor precisa discutir sobre os valores humanos entre os alunos, com o objetivo de torná-los cidadãos preparados para assumirem a responsabilidade de construir uma sociedade que satisfaça as exigências presentes sem comprometer a capacidade das gerações futuras de suprir suas próprias necessidades

A educação ambiental figura como instrumento na promoção do desenvolvimento sustentável, vez que, amparada na ética ecológica, gera uma conscientização acerca da preservação do planeta. Ou seja, devido ao seu compromisso com o desenvolvimento humano e ambiental, auxilia para o despertar da percepção sustentável por meio de mudanças nos valores, nas ações, nos pensamentos, nas metodologias, entre outros hábitos humanos, sob o fundamento de

\footnotetext{
${ }^{24}$ Guedes, J. C.S. (2006). Educação Ambiental nas Escolas de Ensino Fundamental: estudo de caso. Garanhuns: Ed. do auto.

${ }_{25}$ TRAVASSOS, Edson Gomes. A prática da educação ambiental nas escolas. Porto Alegre: Mediação, 2004. $77 \mathrm{p}$

${ }^{26}$ MOREIRA, Antonio Carlos. Educação Ambiental na Escola: O que fazer? Uma Perspectiva Sócio Espacial. São Miguel do Oeste: MCLEE: 2002. Ior p.
} 
uma ética ambientalista, assim entendida como a exteriorização dessa consciência $(\text { MASSINE, 2010 })^{27}$.

De acordo com Milaré (2009) ${ }^{28}$ a educação ambiental tem um papel integrador: combina disciplinas, saberes, ensinamentos, aprendizados, práticas. Sob o ponto de vista pedagógico e educacional, ela contribui para dar unidade e convergência aos diferentes tratamentos que se encontram nos sistemas educacionais. Portanto, a educação ambiental figura como ferramenta para conservar a natureza, auxiliando no desenvolvimento sustentável de uma sociedade ciente de seu papel ambiental, se mostrando para tanto capaz de renovar valores e alterar dogmas presentes na relação entre o homem e o meio ambiente, considerando uma nova dimensão que se incorpora no processo de ensino (SANTOS, 1997) ${ }^{29}$.

Inserir no currículo escolar a educação ambiental, portanto, torna-se fundamental para o desenvolvimento dos educandos, tornando-os cidadãos conscientes e críticos com as questões relacionadas ao meio ambiente. Definir educação ambiental é falar sobre educação dando-lhe uma nova dimensão, contextualizada e adaptada à realidade interdisciplinar e vinculada aos temas ambientais locais e globais (GUERRA \& ABILIO, 2005) ${ }^{30}$.

A reflexão sobre as práticas sociais, em um contexto marcado pela degradação permanente do meio ambiente e do seu ecossistema, envolve uma necessária articulação com a produção de sentidos sobre a educação ambiental. A dimensão ambiental configura-se crescentemente como uma questão que envolve um conjunto de atores do universo educativo, potencializando o engajamento dos diversos sistemas de conhecimento, a capacitação de profissionais e a comunidade universitária numa perspectiva interdisciplinar $(\mathrm{Jacobi}, 2003)^{3 \mathrm{I}}$.

\footnotetext{
${ }^{27}$ MASSINE, M.C.L. Sustentabilidade e Educação Ambiental - Considerações acerca da política nacional de educação ambiental - A Conscientização ecológica em foco. Anais do XIX Encontro Nacional do CONPEDI, Fortaleza - CE, zого.

${ }^{28}$ MILARÉ, É. Direito do ambiente - a gestão ambiental em foco: doutrina, jurisprudência, glossário. 6. ed. rev., atual. e ampl. São Paulo: Revista dos Tribunais, 2009. p. 68-69.

${ }^{29}$ SANTOS, A. S. R. dos. O direito ambiental e a participação da sociedade. In: BEJAMIN, Antônio Herman V.; MILARÉ, É. (Coord.). Revista de direito ambiental. São Paulo, n. 3, jul-set 1997, p. 219.

${ }^{30}$ ABÍLIO, F.J. P.; GUERRA, R. A. T. (Org.). A questão ambiental no ensino de Ciências e a formação continuada de professores de ensino fundamental. João Pessoa: UFPB/FUNAPE, 2005.

${ }^{31} \mathrm{Jacobi}$, P. et al. (2003). Educação ambiental, cidadania e sustentabilidade. Cadernos de pesquisa, II8(3), I89-205.
} 
Por fim, entende-se que a educação ambiental é uma educação que faz com que haja a participação efetiva dos cidadãos no que se refere ao tema, fazendo com que tenha uma "nova aliança" entre o ser humano e a natureza e, acima de tudo, fortalecer e estimular a participação social de todos. Assim a educação ambiental seria construída pela sociedade através dos cidadãos nas diversas discussões acerca dos problemas ambientais do micro ao macro ambiente (Amânico, 2005) ${ }^{32}$.

\subsection{Conceito da educação para o desenvolvimento sustentável}

O conceito EDS surgiu trazendo consigo o mesmo otimismo empregado em relação ao próprio conceito de desenvolvimento sustentável (DS), na década de 8o do século XX. Entretanto, esse conceito tem sofrido certa desconfiança de críticos e pesquisadores do campo da Educação, o que tem contribuído para o debate acerca das relações entre EDS e outras dimensões ou abordagens educativas (FREITAS, 2004) ${ }^{33}$.

Alguns autores, como Gutiérrez, Benayas e Calvo $(2006)^{34}$, afirmam que a ideia de implementar um período para tratar da sustentabilidade por meio da Educação surgiu na Eco-92, com a introdução dos termos Desenvolvimento Humano

e Desenvolvimento Humano Sustentável. O documento elaborado naquela ocasião apresenta a Educação como uma ferramenta para a construção e invenção de novas realidades.

Esses autores definem a Década da Educação para o Desenvolvimento Sustentável (Deds) como em essência, a Década da Educação para o Desenvolvimento Sustentável se propôs a impulsionar uma educação solidária que contribua para uma correta percepção do estado do mundo, que seja capaz de gerar atitudes e compromissos responsáveis, e que prepare os cidadãos para as tomadas de decisões [...] direcionada para alcançar um desenvolvimento culturalmente plural,

\footnotetext{
${ }^{32} \mathrm{AMÂNCIO}, \mathrm{C} . \mathrm{O}$ porque da educação ambiental? Corumbá, MS: Embrapa Pantanal, 2005. 3p. ADM - Artigo de Divulgação na Mídia, n.iog. Disponível em:https://www.cpap.embrapa.br/publicações/online/ADM83 Acesso em: I8 de janeiro de 2022. 33 FREITAS, M. A educação para o desenvolvimento sustentável e a formação de educadores/professores. Perspectiva, v. 22, n. 2, p. 547-575, 2004. Disponível em: http://www.ced.ufsc.br/nucleos/nup/perspectivas.html. Acesso em: 18 jan. 2022.

${ }^{34}$ GUTIÉRREZ, J.; BENAYAS, J.; CALVO, S. Educación para el desarrollo sostenible: evaluación de retos y oportunidades del Decenio 2005-2014. Revista Iberoamericana de Educación, n. 40, p. 25-69, 2006.
} 
socialmente justo e modelos mais inteligentes de interação com os ecossistemas (GUTIÉRREZ; BENAYAS; CALVO, 2006, p. 26.) ). $^{35}$

Ainda de acordo com Gutiérrez, Benayas e Calvo (2006, p. 26.) ) $^{36}$ "Esta mudança de modelos requer ações e instrumentos diversos que transformem nossas atitudes, nosso estilo de vida [...]”. Porém, partindo de uma perspectiva menos otimista acerca da proposta da Deds, Santana e Lima (2009, p. 2.), com base em Fino $(2001)^{37}$, defendem que:

[...] o que tem definido as propostas educacionais ainda hoje, na 'Década da Educação para o Desenvolvimento Sustentável', não são as necessidades do amanhã ou as mudanças a operar na sociedade, e sim interesses momentâneos, acontecimentos e fatos atrelados à demanda do capital [...]

Do mesmo modo, Löwy $(2014)^{38}$, também questiona a legitimidade da proposta da EDS, segundo o autor o interesse por trás da proposta da Deds foi a tentativa de enquadrar a sociedade dentro da lógica hegemônica do capitalismo no período de uma década. A proposta de uma educação guiada pelo DS, bem como a possibilidade de enquadramento em nível global da sociedade a essa proposta, é polêmica dentro das pesquisas no campo da Educação, sobretudo nos EUA, onde a proposta da EDS é bastante conhecida e difundida, havendo várias pesquisas publicadas em revistas internacionalmente reconhecidas que investigaram a questão

(GONZÁLEZ GAUDIANO, 2006; HART; NOLAN, 2008; HEDEFALK; ALMQVIST; ÖSTMAN, 2014) $)^{39}$.

Segundo Hedefalk, Almqvist e Östman (2014, p. 2. $)^{40}$, que trabalharam com educação infantil, tomando por base o trabalho de Scott e Gough (2004), de forma geral, a EDS "tem como objetivo ensinar os alunos como agir criticamente", entretanto tais autores indicam que há duas definições distintas que encontraram em

\footnotetext{
${ }^{35}$ Ibidem;

${ }^{36}$ Ibidem;

${ }^{37}$ SANTANA, J. M.; LIMA, C. C. U. A inserção dos princípios da Ecopedagogia no currículo escolar: uma proposta de educação para a sustentabilidade. In: SEMINÁRIO INTERNACIONAL “EXPERIÊNCIAS DE AGENDAS 2r: OS DESAFIOS DO NOSSO TEMPO”, 2009, Ponta Grossa. Anais $[\ldots]$ 2009, s/p.

${ }^{38}$ LÖWY, M. O que é Ecossocialismo? 2. ed. São Paulo: Cortez, 2014. 128 p.

${ }^{39}$ GONZÁlEZ-GAUDIANO, E. J. Environmental Education: a field intension or in transition. Environmental Education Research, v. 12, n. 3-4, p. 291-300, 2006.

${ }^{40}$ HEDEFALK, M; ALMQVIST, J; ÖSTMAN, L. Education for sustainable development in early childhood education: a review of the research literature. Environmental Education Research, p. I-I6, 2014.
} 
suas pesquisas, a saber: "EDS como uma tripla abordagem à educação baseada em questões relativas à educação sobre, no e para o meio ambiente" (HEDEFALK; ALMQVIST; ÖSTMAN, 2014, p. 4.) e "EDS como uma abordagem à educação, que inclui três dimensões inter-relacionadas (econômicas, sociais e ambientais)" (HEDEFALK; ALMQVIST; ÖSTMAN, 2014, p 4. $)^{4 \mathrm{I}}$.

A primeira definição, na qual a EDS seria uma educação sobre, no e para o meio ambiente, parece ser a definição menos usual, uma vez que não é a definição padrão proposta pela ONU. Entretanto, muitos pesquisadores vêm se ocupando do tema pela perspectiva dessa definição.

Segundo Hedefalk, Almqvist e Östman (2014) ${ }^{42}$, a educação sobre o meio ambiente enfatiza o conhecimento sobre como funcionam os sistemas naturais, tais como os ciclos da água, sistemas ecológicos e como as plantas crescem. Educação no ambiente enfatiza experiências diretas na natureza. Educação para o meio ambiente enfatiza a participação ativa na resolução de problemas ambientais ou tornando escolhas socialmente justas e sustentáveis. A abordagem deve, de acordo com os proponentes dessa definição de EDS, não ser vista como três partes separadas, mas, em vez disso, usada como um todo, a fim de aprender sobre e no meio ambiente e de ser capaz de agir para o ambiente.

Já na segunda definição, a EDS é vista conforme proposição dos mesmos três pilares que sustentam a pirâmide da proposta de DS, o Triple Botton Line, ou seja, economicamente viável (no topo da pirâmide), socialmente justo e ecologicamente correto (ELKINGTON, I994; BOFF, 2012; SARTORI; LATRÔNICO; CAMPOS, 2014 ${ }^{43}$. Esse modo de entender a EDS é o mais usual, uma vez que é a definição clássica constante em muitos documentos dos órgãos oficiais. Segundo os autores estudados:

Outra maneira de definir ESD é a inclusão de dimensões econômica, social e ambiental da sustentabilidade no conteúdo de ensino. Essas dimensões também foram abordadas em vários documentos da ONU (ver, por exemplo, UNCED 1992; UNESCO 2005; Brundtland, 1988). A dimensão ambiental envolve a proteção dos ecossistemas e suas diversidades biológicas.A dimensão social envolve justiça, igualdade e uma abordagem

\footnotetext{
${ }^{41}$ Ibidem;

${ }^{42}$ Ibidem;

43 ELKINGTON, J. Towards the sustainable corporation: Win-win-win business strategies for sustainable development. California Management Review, v. 36, n. 2, p. 90-10o. 1994
} 
democrática. A dimensão econômica envolve uma abordagem financeira aos recursos onde o desenvolvimento econômico afeta os seres humanos e / ou para o ambiente de uma forma positiva. As dimensões destacam as inter-relações entre o desenvolvimento econômico, proteção ambiental e justiça social na educação (Ohman de 20II). Eles também ilustram como os estilos de vida das pessoas, natureza e sociedade estão relacionados uns aos outros (Pramling Samuelsson, 2orI) (HEDEFALK; ALMQVIST; ÖSTMAN, 2014, p. 4. $)^{44}$.

De acordo com esses autores, ambas as definições são pautadas na educação a partir dos preceitos do DS, a grande diferença que as separa é que a primeira é uma derivação da segunda definição que apresentamos, pautada, quase que em sua totalidade, unicamente na preservação do ambiente natural, enquanto que, no segundo caso, outros aspectos são incluídos (social e também econômico).

E, ainda segundo os autores, a definição de EDS como a educação baseada em questões relativas à "educação sobre, no e para o meio ambiente" se concentraria na EA, como se só houvesse uma forma de se pensar a EA, como se toda EA fosse conservacionista 5 e ainda restrita ao campo das Ciências Naturais. Pois, na perspectiva de Hedefalk; Almqvist; Östman (2014, p. 5-6.) 45 $^{45}$

A EA resulta em um campo de conhecimento com base em dados científicos. Juízos de valor éticos em conexão com o problema da sustentabilidade com base em fontes externas da ciência não são evidentes. A resposta certa de como agir é encontrada na ciência.

Ademais, ainda de acordo a argumentação dos referidos autores, a definição de EDS que mais teria, implícita em si, a ideia da emancipação e criticidade seria aquela definição em que a EDS é sustentada pelos pilares do DS (HEDEFALK; ALMQVIST; ÖSTMAN, 2014, p 4$)^{46}$.

Definição que, como vimos, é a mais aceita e disseminada internacionalmente, principalmente nos países da Europa e EUA, nos quais há uma proposta de suposta superação dos limites da EA pela EDS, e, de maneira geral, o principal objetivo da EDS seria “ensinar aos alunos como agir criticamente" (SCOTT; GOUGH, 2004 apud HEDEFALK; ALMQVIST; ÖSTMAN, 2014, p. 2.) $)^{47}$.

\footnotetext{
${ }^{44}$ HEDEFALK, M; ALMQVIST, J; ÖSTMAN, L. Education for sustainable development in early childhood education: a review of the research literature. Environmental Education Research, p. I-16, 2014.

${ }^{45}$ Ibidem;

${ }^{46}$ Ibidem;

${ }^{47}$ Ibidem;
} 
González-Gaudiano (2006, p. 291. $)^{4^{8}}$, apoiado nos trabalhos de outros autores que se preocuparam em discutir a controversa proposta do DS e da EDS, principalmente Hukcle (1983), Fien (1993) e Tilbury (1995), indica que, para muitos autores, a EDS é entendida como

[...] uma versão superior de educação ambiental que trará contribuiç̃̃es potentes para a solução dos problemas de hoje [...] oferecendo uma estrutura que será capaz de transcender ao 'limitado' âmbito da educação ambiental [...] elevando processos educativos a um nível em que as ideologias profundas dentro educações ambientais podem ser ultrapassadas.

De acordo com Sauvé (1997) ${ }^{49}$ e Lima (2003), de fato a EDS teve como proposta superar a EA desenvolvida nas escolas dos países pertencentes à União Europeia e dos EUA, pois nessas regiões a EA começava a cair em descrédito, uma vez que parecia não estar contribuindo para a superação da crise ambiental de nosso tempo, sobretudo por parecer compreender a questão ambiental de forma reducionista, ou seja, como simples questão ecológica, desconsiderando seus aspectos sócio-históricos e políticos.

De modo geral, enquanto no Brasil a EDS é vista de modo despolitizado, nos países europeus e nos EUA é a EA que é vista dessa maneira, ou seja, de forma naturalista e "biologizada" (LIMA, 2003; FREITAS, 2004; GONZÁLEZGAUDIANO, 2006) $)^{50}$.

A visão atual que há acerca da EDS nos países desenvolvidos, sobretudo na Europa e nos EUA, se assemelha ao otimismo empregado pela EA na sua gênese, ou até mesmo, à própria proposta do DS, vista até os dias de hoje com otimismo em muitas esferas da sociedade.

Nos países da América Latina, a proposta de uma educação direcionada pelo e para o DS é encarada com reservas pelos educadores e pesquisadores da área. Por isso, muitas das críticas a essa proposta, encontradas nas pesquisas sobre EA, advêm

$4^{8}$ GONZÁLEZ-GAUDIANO, E. J. Environmental Education: a field intension or in transition. Environmental Education Research, v. 12, n. 3-4, p. 291-300, 2006.

49 SAUVÉ, L. Educação ambiental e desenvolvimento sustentável: uma análise complexa. Revista de Educação Pública, v. 6, n. ıo, 1997.

so LIMA, G. C. O discurso da sustentabilidade e suas implicações para a educação. Ambiente \& Sociedade, São Paulo, v. 6 n. 2, p. 99-II9, 2003. 
dessa região do Globo (GONZÁLEZ-GAUDIANO, 2006) ${ }^{5 \mathrm{I}}$, ainda que tenha sido também em um país da América Latina o local de idealização de uma proposta pedagógica (alguns a entendem como uma prática pedagógica da EA) que adota justamente os princípios da EDS, conhecida como Ecopedagogia ou Pedagogia da Terra, tal qual a conhecemos hoje, sobretudo por meio dos trabalhos do costariquenho Gutiérrez e também de Moacir Gadotti no Brasil.

O trabalho pedagógico envolvendo os ODS tem sido realizado, mundialmente, na perspectiva da Educação para o Desenvolvimento Sustentável (EDS). O conceito de EDS nasceu da necessidade de educação para abordar a crescentes desafios ambientais que o planeta enfrenta. A EDS, formulada em 2005, pode ser conceituada como uma educação que contribui para que as pessoas pensem criticamente, identificando elementos insustentáveis em suas vidas e na sociedade, e ajam por mudanças sociais e ambientais positivas.

O lançamento da Década das Nações Unidas da Educação para o Desenvolvimento Sustentável (2005-2014) $)^{52}$ desencadeou um movimento global para reorientar a educação para os desafios do desenvolvimento sustentável. A UNESCO coordena mundialmente o Programa de Ação Global sobre EDS (2014-2030) ${ }^{53}$, criado para implementação e monitoramento das ações da década. Esse programa visa garantir que os princípios da EDS sejam promovidos na educação formal, não formal e informal, incluindo questões-chaves sobre desenvolvimento sustentável no ensino e na aprendizagem.

A busca do desenvolvimento sustentável exige um amplo movimento voltado à mudança de mentalidades, atitudes e comportamentos. Segundo a Declaração de Incheon (UNESCO, 2015, p. 8) ${ }^{54}$, é por meio da EDS que se "desenvolvem habilidades, valores e atitudes que permitem aos cidadãos levar vidas saudáveis e plenas, tomar decisões conscientes e responder a desafios locais e globais”. Por isso, a

sı GONZÁlEZ-GAUDIANO, E. J. Environmental Education: a field intension or in transition. Environmental Education Research, v. 12, n. 3-4, p. 291-300, 2006.

${ }^{52}$ UNESCO (2005). Organização das Nações Unidas para a Educação, a Ciência e a Cultura. Década da educação das Nações Unidas para um desenvolvimento sustentável, 2005-2014: documento final do esquema internacional de implementação. Brasília: UNESCO, 2005. Disponível em:http://unesdoc.unesco.org/images/oor3/oo1399/139937por.pdf . Acesso em: 20 jan. 2022.

53 Declaração de Incheon: Educação 2030: Rumo a uma Educação de Qualidade Inclusiva e Equitativa e à Educação ao Longo da Vida para Todos - UNESCO Digital Library.
Declaração de Incheon.
Brasília, 2015.
Disponível
em:

〈http://unesdoc.unesco.org/images/o023/o0233I/233137POR.pdf〉. Acesso em: 20 jan. 2022 
EDS é entendida como parte da educação de qualidade e da aprendizagem ao longo da vida. Relaciona-se diretamente com o ODS 4 e indiretamente com os demais ODS, pois dá suporte aos indivíduos para que transformem seu próprio comportamento, aprendam a participar de processos coletivos e engajem-se em mudanças sociais, econômicas e políticas em direção à sustentabilidade. No caderno sobre o ODS 4 , esse tema será tratado com mais profundidade (UNESCO, 2013) ${ }^{55}$.

\begin{tabular}{|l|l|}
\hline \multicolumn{2}{|c|}{ O esquema a seguir sintetiza as habilidades encorajadas pela EDS. } \\
\hline \multicolumn{2}{|c|}{ Principais dimensões conceituais da EDS } \\
\hline Habilidades cognitivas & $\begin{array}{l}\text { Os estudantes adquirem conhecimentos, } \\
\text { compreensão e raciocínio crítico sobre questões } \\
\text { globais sobre e e e a } \\
\text { interconectividade/interdependência } \\
\text { países e entre diferentes populações. }\end{array}$ \\
\hline Habilidades comportamentais socioemocionais & $\begin{array}{l}\text { Os estudantes têm o sentimento de pertencer a } \\
\text { uma humanidade comum, ao compartilhar } \\
\text { valores e responsabilidade e possuir direitos. } \\
\text { Os estudantes demonstram empatia, } \\
\text { solidariedade e respeito por diferenças e } \\
\text { diversidade }\end{array}$ \\
\hline $\begin{array}{l}\text { Os estudantes agem de forma efetiva e } \\
\text { responsável nos contextos local, nacional e } \\
\text { global, em prol de um mundo mais pacífico e } \\
\text { sustentável }\end{array}$ \\
\hline
\end{tabular}

Fonte: Adaptado de UNESCO, 2022.

Em âmbito nacional, a EDS procura pontos de convergência com as políticas públicas existentes que se relacionam à defesa do meio ambiente e de estilos de vida sustentáveis.

2.3. A relação entre educação para o desenvolvimento sustentável (eds) e educação para o ambiente (EA)

A Educação para o Desenvolvimento Sustentável (EDS) e a Educação Ambiental (EA) possuem diferentes compreensões sobre o conceito de sustentabilidade, mas convergem em pontos essenciais. Ambas pretendem, por exemplo, formar cidadãos críticos, capazes de atuar individual e coletivamente em prol de transformações sociais, tendo como horizonte a criação de sociedades em que

\footnotetext{
55 Esquema desenvolvido pela UNESCO com base em contribuições de especialistas em Educação para a Cidadania Global (ECG) e Educação para o Desenvolvimento Sustentável (EDS) de todo o mundo e na consultoria técnica sobre ECG, realizada em Seul, Coreia do Sul, em 2013, e no Primeiro Fórum da UNESCO sobre Educação para a Cidadania Global, que ocorreu em Bangkok, Tailândia, em 2013
} 
a coexistência entre todos os seres - humanos ou não - torne-se realidade (UNESDOC DIGITAL LIBRARY, 2020 $)^{56}$.

A maioria dos especialistas inquiridos no âmbito do ESDebate (Hesselink, e outros, 200o) parece «encarar a EDS como um novo estado evolutivo ou uma nova geração de EA» (Hesselink, e outros, 2000, p. 2I $)^{57}$.

Há, contudo, outras opiniões. Caride, e Meira $(2004)^{58}$, por exemplo, argumentam que «a Educação Ambiental para o Desenvolvimento Humano Sustentado, ou como se queira denominar, arrastada pela sedução destes conceitos, poderá derivar numa perigosa indefinição...» (p.197), e realçam o perigo de que «debaixo de um discurso aparentemente comprometido com a mudança social [...] se pode estar salvaguardando a mesma orientação de desenvolvimento, da cultura e da política económica que tem gerado os problemas sócio-ecológicos existentes» (p. $198)^{59}$.

Defendendo que «os enquadramentos que propiciam o saber e o saber fazer educativo-ambiental não poderão restringir-se apenas a suscitar atitudes nas pessoas para um desenvolvimento sustentável» $(\text { p. } 278)^{60}$, parecem encaminhar-se mais no sentido de considerar a EDS como uma parte da EA (Freitas, no prelo b). McKeown, e Hopkins (2002) ${ }^{6}$, por seu turno, defendem que a EDS e a EA «têm similaridades», mas são abordagens «distintas, ainda que complementares», e que é importante que «a EA e a EDS mantenham agendas, prioridades e desenvolvimentos programáticos diferentes» $(\text { p. } 127)^{62}$.

A concepção aqui trabalhada comunga com a perspectiva de cidadania local e global, aquela em que os estudantes compreendem seus direitos e responsabilidades para a construção de um mundo melhor para todos. Isso deve incluir,

\footnotetext{
${ }^{56}$ Educação para o desenvolvimento sustentável na escola: caderno introdutório - UNESCO Digital Library acessado em 17 jan. 2022.

${ }^{57}$ HESSELINK, F.; KEMPEN, P., e WALLS, A. van (200o): EDSdebate, Suiza, Gland e Cambridge, IUCN.

${ }^{8}$ CARIDE, J. A., e MEIRA, P. (2004): Educação ambiental e desenvolvimento humano, Lisboa, Instituto Piaget.

59 Ibidem;

${ }^{60}$ Ibidem;

6r MCKEOWN R., e HOPKINS C. (2002): «Education for Sustainable Development. An International Perspective», in Environmental Education Research, vol. 9, n.요 I, pp. II7-I28.

${ }_{62}$ MCKEOWN R., e HOPKINS C. (2002): «Education for Sustainable Development. An International Perspective», in Environmental Education Research, vol. 9, n. ${ }^{\mathrm{O}}$ I, pp. II7-I28.
} 
necessariamente, o compromisso com a justiça social, a sustentabilidade ambiental e os direitos humanos.

\section{CONCLUSÃO}

O objetivo deste artigo foi apresentar a gênese de uma concepção de EA associada ao desenvolvimento sustentável e um debate importante que surgiu ao longo de sua trajetória, com a proposta de educação para o desenvolvimento sustentável (EDS). Para tal, foram resgatados aspectos históricos e conceituais dos movimentos observados no mundo desde a criação da Unesco. Assim, diante do exposto, pode-se pensar em algumas considerações que visem dar sentindo e permitir incorporar a EA nos cursos de Administração e em outros de nível superior, considerando que a legislação nacional sobre essa matéria foi profundamente influenciada pelos documentos intergovernamentais mencionados, além dos que foram produzidos aqui, como a Declaração de Brasília, de 1997 (BRASIL, 1997) ${ }^{63}$.

Um dos aspectos a ser destacado é que a EA deve ser implantada por meio de uma abordagem interdisciplinar, como diz a Carta de Belgrado, ou abordagens multidisciplinar, interdisciplinar e transdisciplinar, como estabelece a Política Nacional de Educação Ambiental (BRASIL, 1999, art. $\left.4^{\circ}\right)^{64}$.

A EA não deve implantada como disciplina específica (BRASIL, 1999, art. $\left.{ }_{10}{ }^{6}\right)^{65}$, mas incluída em todas as oportunidades de ensino, como um processo contínuo que deve se estender para fora das instalações escolares, de modo a considerar o meio ambiente em suas múltiplas dimensões. As questões ambientais requerem urgência, a adesão das instituições de ensino, dentre as muitas existentes, como um meio para apressar o aprendizado sobre a educação ambiental como caminho para o desenvolvimento sustentável.

\section{REFERÊNCIAS}

ABÍLIO, F.J. P.; FLORENTINO, H. da S. Percepção e atividades integradoras de educação ambiental com educandos do ensino médio de Soledade-PB. João Pessoa: UFPB, 2008.

\footnotetext{
63 BRASIL. Ministério do Meio Ambiente. Declaração de Brasília. 1997. Disponível em:http://www.mma.gov.br/port/sdi/ea/infgeral.cfm . Acesso em: 20 jan. 2022.

${ }^{64}$ BRASIL. Lei n. 9.795, de 27 de abril de 1999. Institui a Política Nacional de Educação Ambiental. Diário Oficial da União, Brasília, seção ı, p. I-4, abr. 1999.

${ }^{65}$ Ibidem;
} 
ABÍLIO, F.J. P.; GUERRA, R. A. T. (Org.). A questão ambiental no ensino de Ciências e a formação continuada de professores de ensino fundamental. João Pessoa: UFPB/FUNAPE, 2005.

Almeida, J. R. (2006). Gestão ambiental: para o desenvolvimento sustentável. Rio de Janeiro: Thex.

AMÂNCIO, C. O porque da educação ambiental? Corumbá, MS: Embrapa Pantanal, 2005. 3p. ADM - Artigo de Divulgação na Mídia, n.ıo9. Disponível em:https://www.cpap.embrapa.br/publicações/online/ADM83 Acesso em: I8 de janeiro de 2022.

ASSEMBLÉIA GERAL DAS NAÇÕES UNIDAS. Pacto internacional dos direitos econômicos, sócias e culturais. Resolução 2.200-A, 1966. Ratificado pelo Brasil em 24 jan. 1992.

ASSIS, A. R. S.; CHAVES, M. R. A degradação ambiental e a sustentabilidade. Revista Nacional de Gerenciamento de Cidades, v. or, n. 02, p.5874,2013

Barbieri, J. C. \& Silva, D. (20II). Desenvolvimento sustentável e educação ambiental: uma trajetória comum com muitos desafios. Revista de Administração Mackenzie, São Paulo, SP, I2(3), 51-82, maio/jun.

BARBIERI, José Carlos; SILVA, Dirceu da. Desenvolvimento sustentável e educação ambiental: uma trajetória comum com muitos desafios. RAM, Rev. Adm. Mackenzie (Online), São Paulo, v. I2,n. 3,p. 51-82,JunezoII . Disponível em: $<$ http://www.scielo.br/scielo.php?script=sci_arttext\&pid=SI67869712011000300004\&1 $\mathrm{ng}=\mathrm{en} \& \mathrm{nrm}=\mathrm{iso}>$. Acesso em: 16 jan. 2022.

BRASIL. Lei n. 9.795, de 27 de abril de 1999. Institui a Política Nacional de Educação Ambiental. Diário Oficial da União, Brasília, seção I, p. I-4, abr. 1999.

BRASIL. Ministério do Meio Ambiente. Declaração de Brasília. 1997. Disponível em:http://www.mma.gov.br/port/sdi/ea/infgeral.cfm . Acesso em: 20 jan. 2022.

CARIDE, J. A., e MEIRA, P. (2004): Educação ambiental e desenvolvimento humano, Lisboa, Instituto Piaget.

Carta de Belgrado. (1975). Uma estrutura global para a educação ambiental. Recuperado em 16 jan. 2022, de http://www.fzb.rs.gov.br/upload/4_de_belgrado.pdf.

Carvalho, I. C. M. (20II). Educação Ambiental: a formação do sujeito ecológico (5a ed.). São Paulo, SP: Cortez.

CNUMAH. Declaração de Estocolmo sobre o ambiente humano. Estocolomo, 1972. Disponível em: http://www.educacaoambiental.pro.br/DeclaraAmbienteano.pdf Acesso em: 20 janeiro 2022. 
Declaração de Incheon: Educação 2030: Rumo a uma Educação de Qualidade Inclusiva e Equitativa e à Educação ao Longo da Vida para Todos - UNESCO Digital Library.

Educação para o desenvolvimento sustentável na escola: caderno introdutório UNESCO Digital Library acessado em i7 jan. 2022.

ELKINGTON, J. Towards the sustainable corporation: Win-win-win business strategies for sustainable development. California Management Review, v. 36, n. 2, p. 90-100. 1994.

Esquema desenvolvido pela UNESCO com base em contribuições de especialistas em Educação para a Cidadania Global (ECG) e Educação para o Desenvolvimento Sustentável (EDS) de todo o mundo e na consultoria técnica sobre ECG, realizada em Seul, Coreia do Sul, em 2013, e no Primeiro Fórum da UNESCO sobre Educação para a Cidadania Global, que ocorreu em Bangkok, Tailândia, em 2013.

FREITAS, M. A educação para o desenvolvimento sustentável e a formação de educadores/professores. Perspectiva, v. 22, n. 2, p. 547-575, 2004. Disponível em: http://www.ced.ufsc.br/nucleos/nup/perspectivas.html. Acesso em: I8 jan. 2022.

GONZÁLEZ-GAUDIANO, E. J. Environmental Education: a field intension or in transition. Environmental Education Research, v. 12, n. 3-4, p. 291-300, 2006.

Guedes, J. C.S. (2006). Educação Ambiental nas Escolas de Ensino Fundamental: estudo de caso. Garanhuns: Ed. do auto.

GUTIÉRREZ, J.; BENAYAS, J.; CALVO, S. Educación para el desarrollo sostenible: evaluación de retos y oportunidades del Decenio 2005-2014. Revista Iberoamericana de Educación, n. 40, p. 25-69, 2006.

HEDEFALK, M; ALMQVIST, J; ÖSTMAN, L. Education for sustainable development in early childhood education: a review of the research literature. Environmental Education Research, p. I-16, 2014.

HESSELINK, F.; KEMPEN, P., e WALLS, A. van (2000): EDSdebate, Suiza, Gland e Cambridge, IUCN.

HOHENDORFF, J. V. Como escrever um artigo de revisão de literatura. In: KOlleR, S. H.; COUTO, M. C.; HOHENDORFF, J. V. Manual de produção científica. I ed., vol. I. Porto Alegre, RS, Brasil: Porto, 20I4. p. I9I.

JACOBI, P. et al. (2003). Educação ambiental, cidadania e sustentabilidade. Cadernos de pesquisa, II8(3), I89-205.

LIMA, G. C. O discurso da sustentabilidade e suas implicações para a educação. Ambiente \& Sociedade, São Paulo, v. 6 n. 2, p. 99-119, 2003. 
LÖWY, M. O que é Ecossocialismo? 2. ed. São Paulo: Cortez, 2014. I28 p.

MASSINE, M.C.L. Sustentabilidade e Educação Ambiental - Considerações acerca da política nacional de educação ambiental - A Conscientização ecológica em foco. Anais do XIX Encontro Nacional do CONPEDI, Fortaleza - CE, 20 о.

MCKEOWN R., e HOPKINS C. (2002): «Education for Sustainable Development. An International Perspective», in Environmental Education Research, vol. 9, n. I, pp. II7-I28.

MILARÉ, É. Direito do ambiente - a gestão ambiental em foco: doutrina, jurisprudência, glossário. 6. ed. rev., atual. e ampl. São Paulo: Revista dos Tribunais, 2009. p. 68-69.

MOREIRA, Antonio Carlos. Educação Ambiental na Escola: O que fazer? Uma Perspectiva Sócio - Espacial. São Miguel do Oeste: MCLEE: 2002. Ior p.

MORIN, Edgar. Terra-pátria. 2. ed. Porto Alegre: Sulina, I995. p. 69.

OLIVEIRA, Daniel Barbosa de. Material de Apoio sobre Educação: Conceito de Educação. Paracatu/SC. 2009. Disponível em: $\langle$ http://www.ebah.com.br/content/ABAAAATl8AJ/conceito-educacao〉. Acesso em is set 2009 .

PHILIPPI JR, Arlindo, CAFFÉ ALVES, Alaôr. Curso interdisciplinar de direito ambiental. São Paulo: Manole, 2005. p. I4I.

POTT, C. M.; ESTRELA, C. C. Histórico ambiental: desastres ambientais e o despertar de um novo pensamento. Estudos Avançados, v. 31, n. 89, p.27I-283, 2017.

SANTANA, J. M.; LIMA, C. C. U. A inserção dos princípios da Ecopedagogia no currículo escolar: uma proposta de educação para a sustentabilidade. In: SEMINÁRIO INTERNACIONAL "EXPERIÊNCIAS DE AGENDAS 2r: OS DESAFIOS DO NOSSO TEMPO”, 2009, Ponta Grossa. Anais [...] 2009, s/p.

SANTOS, A. S. R. dos. O direito ambiental e a participação da sociedade. In: BEJAMIN, Antônio Herman V.; MILARÉ, É. (Coord.). Revista de direito ambiental. São Paulo, n. 3, jul-set 1997, p. 219.

SAUVÉ, L. Educação ambiental e desenvolvimento sustentável: uma análise complexa. Revista de Educação Pública, v. 6, n. Io, 1997.

TRAVASSOS, Edson Gomes. A prática da educação ambiental nas escolas. Porto Alegre: Mediação, 2004. 77 p

Tristão, M. \& Jacobi, P. R. (2010). Educação ambiental e os movimentos de um campo de pesquisa. São Paulo: Annablume. 
UNESCO (2005). Organização das Nações Unidas para a Educação, a Ciência e a Cultura. Década da educação das Nações Unidas para um desenvolvimento sustentável, 2005- 2014: documento final do esquema internacional de implementação. Brasília: UNESCO, 2005. Disponível em: http://unesdoc.unesco.org/images/oo13/or.pdf . Acesso em: 20 jan. 2022.

UNESCO, 1987. Congreso Internacional UNESCO/PNUMA sobre la educacion y la Formacion Ambientales, Moscou. In: Educação Ambiental, Situação Espanhola e Estratégia Internacional. DGMA-MOPU, Madrid.

UNESCO. Declaração de Incheon. Brasília, 2015. Disponível em: $\langle$ http://unesdoc.unesco.org/images/o023/o0233I/233137POR.pdf $\rangle$. Acesso em: 20 jan. 2022. 